\title{
The aortopathy of bicuspid aortic valve disease has distinctive patterns and usually involves the transverse aortic arch
}

Shafie S. Fazel, MD, PhD, ${ }^{a}$ Hari R. Mallidi, MD, ${ }^{a}$ Richard S. Lee, MD, ${ }^{a}$ Michael P. Sheehan, MSN, RN, FNP,

David Liang, MD, PhD, ${ }^{c}$ Dominik Fleischman, MD, ${ }^{\mathrm{b}}$ Robert Herfkens, MD, ${ }^{\mathrm{b}}$ R. Scott Mitchell, MD, ${ }^{\mathrm{a}}$ and D. Craig Miller, MD

丹 Supplemental material is available online.
From the Departments of Cardiothoracic Surgery $^{\mathrm{a}}$ and Radiology ${ }^{\mathrm{b}}$ and the Cardiovascular Medicine Division, ${ }^{\mathrm{c}}$ Stanford University Medical School, Stanford, Calif.

Read in part at the Thirty-third Annual Meeting of the Western Thoracic Surgical Association, Santa Ana Pueblo, NM, June 27-30, 2007.

Received for publication Aug 2, 2007; revisions received Dec 22, 2007; accepted for publication Jan 23, 2008.

Address for reprints: D. Craig Miller, MD, Department of Cardiothoracic Surgery, Falk Cardiovascular Research Center, Stanford University School of Medicine, Stanford, California 94305-5247 (E-mail: dcm@stanford.edu).

J Thorac Cardiovasc Surg 2008;135:901-7 $0022-5223 / \$ 34.00$

Copyright (C) 2008 by The American Association for Thoracic Surgery

doi:10.1016/j.jtcvs.2008.01.022
Objectives: Bicuspid aortic valves are associated with a poorly characterized connective tissue disorder that predisposes to aortic catastrophes. Because no criterion exists dictating the appropriate extent of aortic resection in aneurysmal disease of the bicuspid aortic valve, we studied the patterns of aortic dilation in this population.

Methods: Sixty-four patients with bicuspid aortic valves who underwent computed tomographic or magnetic resonance angiography and echocardiography were retrospectively identified between January 2002 and March 2006. Orthonormal 2-dimensional or 3-dimensional aortic diameters were measured at 10 levels. Agglomerative hierarchic clustering with centered correlation distance measurements and complete linkage analysis was used to detect distinct patterns of aortic dilatation.

Results: Mean aortic diameter was $28.1 \pm 0.7 \mathrm{~mm}$ at the annulus and $21.7 \pm 0.4 \mathrm{~mm}$ at the diaphragmatic hiatus. The aorta was largest in the tubular ascending aorta (45.9 $\pm 1.0 \mathrm{~mm}$ ). Compared with the descending aorta, the transverse aortic arch was also dilated $(P<.01)$. Cluster analysis showed 4 patterns of aortic dilatation: cluster I, aortic root alone $(\mathrm{n}=8,13 \%)$; cluster II, tubular ascending aorta alone $(\mathrm{n}=9,14 \%)$; cluster III, tubular portion and transverse arch $(\mathrm{n}=18,28 \%)$; and, cluster IV, aortic root and tubular portion with tapering across the transverse arch $(n=29,45 \%)$.

Conclusion: Distinct patterns of aortic dilatation in patients with bicuspid aortic valves call for an individualized degree of aortic replacement to minimize late aortic complications and reoperation. Patients in clusters III and IV should have transverse arch replacement (plus concomitant root replacement in cluster IV). Patients in cluster I should undergo complete aortic root replacement, whereas in patients in cluster II supracommissural ascending aortic grafting is adequate.

B icuspid aortic valves (BAVs) are the most common congenital cardiovascular malformation, occurring in $0.9 \%$ to $2 \%$ of the population and affecting approximately 4 million persons in the United States. ${ }^{1}$ BAVs are also the most common cause of aortic valve disease in patients younger than 70 years in North America. ${ }^{2}$ Echocardiographic examination of the aortic root and ascending aorta in patients with BAVs has demonstrated more aortic dilatation than in subjects with tricuspid aortic valves. ${ }^{3-6}$ The aortic enlargement in patients with BAVs is typically asymmetric ${ }^{3}$ and might involve the aortic arch. ${ }^{7}$ Even in patients with BAV disease without gross dilation of the ascending aorta, distances between the aortic valve and point of maximum diameter of the ascending aorta at the outer and inner curve are longer, suggesting that the aorta is also elongated. ${ }^{8}$ Aortic aneurysmal disease in the BAV is due to an aortopathy ${ }^{9}$ that is present independently of valvular abnormalities or hemodynamic factors. ${ }^{2,10}$ Even in the absence of aortic dilation, this aortopathy causes abnormal aortic mechanical properties. ${ }^{11}$

The most important clinical consequence of an enlarged ascending aorta and the underlying aortopathy is the higher incidence of aortic rupture and aortic dissection. The presence of a BAV increases the risk of aortic dissection 9-fold and puts the 


\author{
Abbreviations and Acronyms \\ $\mathrm{AI}=$ aortic insufficiency \\ $\mathrm{BAV}=$ bicuspid aortic valve \\ CTA = computed tomographic angiography \\ $\mathrm{CVG}=$ composite valve graft \\ 2-D $=2$-dimensional \\ 3-D $=3$-dimensional \\ ICC = interclass correlation \\ MRA $=$ magnetic resonance angiography
}

patient at risk of aortic dissection at a younger age. ${ }^{12,13}$ Notably, aortic dissection usually occurs in the presence of a normally functioning BAV. ${ }^{12,14}$

Although it is clear that BAV disease is associated with proximal aortic dilation, controversy exists concerning the extent of thoracic aortic involvement, mainly because the majority of studies to date have only used echocardiography to detect aortic dilatation. ${ }^{15}$ Herein we document thoracic aortic morphology in patients with BAVs using computed tomographic angiography (CTA) or magnetic resonance angiography (MRA). We then used hierarchic clustering, a tool used to automatically detect data clusters in gene-array studies, ${ }^{16}$ to identify 4 distinct patterns of aortic involvement. These 4 distinct clusters argue that a custom-tailored surgical approach is most appropriate in dealing with the dilated aorta in the setting of a BAV.

\section{Materials and Methods Patients and Methods}

The time interval of this retrospective review extended from January 1, 2002, to March 1, 2006. Only patients with thoracic aortic imaging with either CTA or MRA were included. The patients were identified by means of electronic query of the radiologic (initially identified 55 patients) and echocardiographic (initially identified 285 patients) databases for the key term "BAV" in either the requisition or in the text field of the report. The surgical database was reviewed manually to identify patients with BAVs who had undergone cardiovascular surgical intervention. A total of 102 patients with BAVs had complete radiologic examination of the thoracic aorta. Patients with only postoperative images $(n=18)$, repaired aortic coarctation ( $n$ $=10)$, and aortic dissection $(n=10)$ were excluded from further analysis. The final analyzed cohort comprised 64 patients, of whom 62 also had a Stanford echocardiogram. The echocardiographic pattern of cusp fusion was recorded in 44 patients on echocardiographic rereview by one of the investigators. Average patient age was $45 \pm 1$ years (range, 18-75 years). Of the 64 patients, 49 were men.

Thoracic aortic diameter was measured at 10 levels: (1) aortic annulus, (2) sinuses of Valsalva, (3) sinotubular junction, (4) tubular portion of the ascending aorta, (5) proximal to the innominate artery (or common trunk in case of a bovine arch), (6) distal to the innominate artery (or common trunk), (7) proximal to the left subclavian artery, (8) distal to the left subclavian artery, (9) proximal descending aorta, and (10) distal descending thoracic aorta at the level of the diaphragmatic hiatus (Figure 1). Aortic measurements were made in the orthonormal plane to the aorta by using 3-dimensional (3-D) reconstructions of the thoracic aorta or 2-dimensional (2-D) axial images when 3-D images were not available. Measurements from the 3-D images were obtained in arbitrary pixels that were converted to metric measurements by normalizing to the aortic diameter measured at the diaphragmatic hiatus on both the 3-D and 2-D axial images. This aortic level was chosen for determining the correction factor because the 2-D axial cuts are most likely to be orthonormal to the longitudinal axis of the descending thoracic aorta here in these young patients. Correlation between the 3-D and 2-D axial measurements was determined in 10 randomly selected patients who had both sets of images available for analysis. Interobserver variability was determined by comparing measurements made by 2 independent blinded observers in another 10 randomly chosen patients.

\section{Statistical Analysis}

Data are presented as means \pm 1 standard error of the mean. The aortic diameter at various levels was compared with the diameter of the aorta at the diaphragmatic hiatus to detect patterns of aortic dilation by using analysis of variance followed by the Dunnett post hoc test. The diameter of the aorta was compared at various levels to detect differences between groups by using the unpaired nonequal variance Student $t$ test. The interclass correlation (ICC) technique was used to calculate interobserver variability from both the 2-D axial and 3-D reconstructed images. Interobserver variability at distinct aortic locations was measured with the Bland-Altman confidence intervals method. Hierarchic cluster analysis was performed with the Hierarchical Clustering Explorer version 3.5 (University of Maryland, www.cs.umd.edu/hcil/hce). The data were first plotted after normalization by using the within-patient $z$ score. Complete linkage analysis with Pearson correlation coefficient similarity measurement was used to generate the clusterogram.

\section{Results}

Overall interobserver variability was minimal: ICCs of 0.91 for the 2-D measurements and 0.88 for the 3-D measurements. The overall correlation between 2-D and 3-D measurements was excellent, with an ICC of 0.85 (see Figure E1). The interobserver variability at various aortic locations by both 2-D and 3-D measurements assessed by using the BlandAltman method is summarized in Table E1. Overall, the reliability of the various 2-D and 3-D measurements was very good.

A mean aortic valve gradient of greater than $10 \mathrm{~mm} \mathrm{Hg}$ (aortic stenosis) was present in $39 \%$ (24/62) of patients for whom echocardiographic reports were available. The distribution of aortic gradients was as follows: 10 to $25 \mathrm{~mm} \mathrm{Hg}, \mathrm{n}=11 ; 26$ to $50 \mathrm{~mm} \mathrm{Hg}, \mathrm{n}=10$; and greater than $50 \mathrm{~mm} \mathrm{Hg}, \mathrm{n}=3$. The mean aortic valve gradient in patients who had any flow acceleration across the valve $(\mathrm{n}=42)$ was $21.6 \pm 3.2 \mathrm{~mm}$ $\mathrm{Hg}$. Thirty-nine patients had aortic insufficiency (AI), which was distributed as follows: $1+\mathrm{AI}, \mathrm{n}=13 ; 2+\mathrm{AI}, \mathrm{n}=15$; $3+\mathrm{AI}, \mathrm{n}=9$; and $4+\mathrm{AI}, \mathrm{n}=2$. In patients with AI, the direction of the regurgitant jet was in a commissure in 2 patients, central in 6 patients, and eccentric and directed along the anterior leaflet of the mitral valve in 19 patients. 


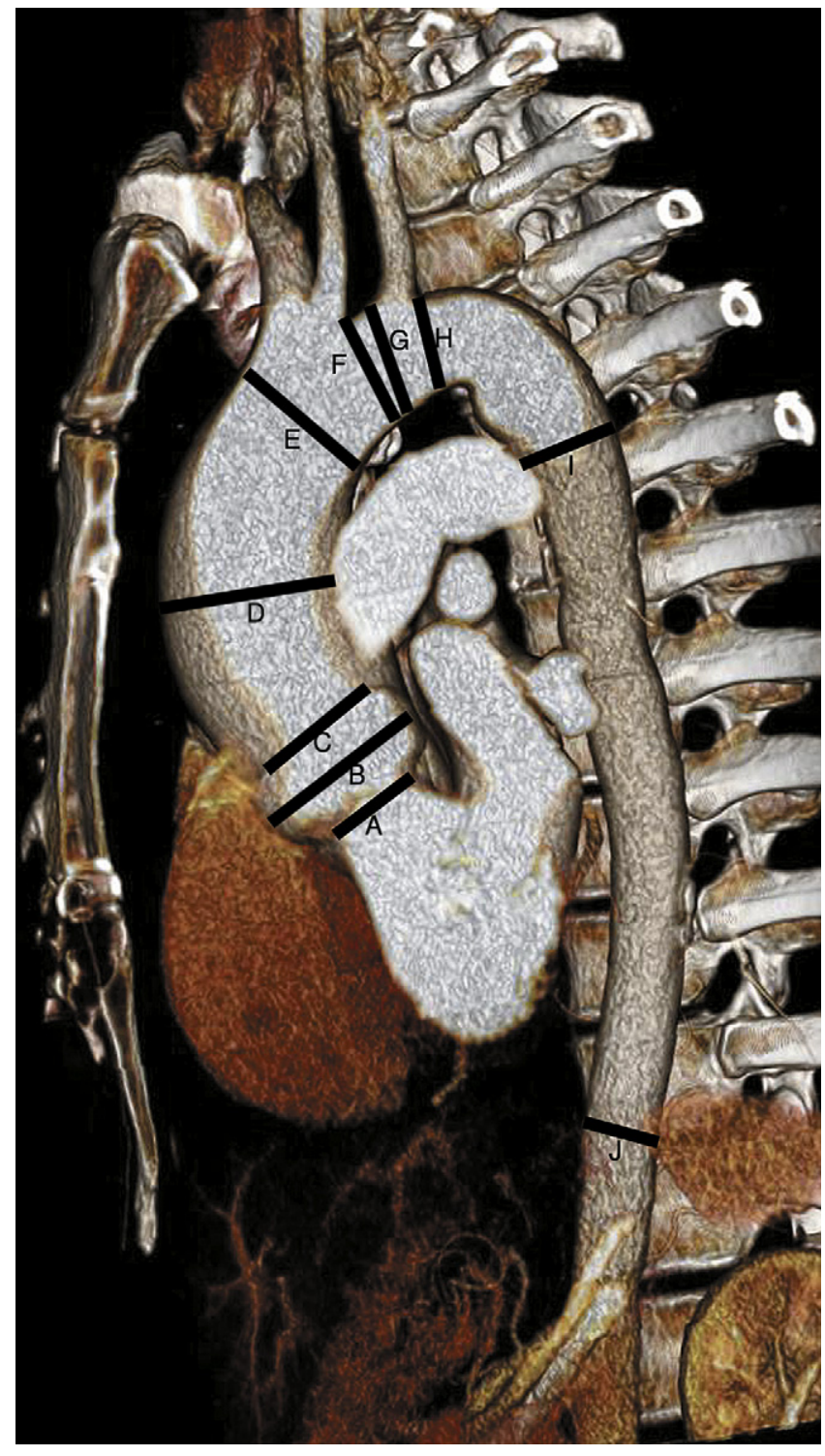

Figure 1. Three-dimensional computed tomographic angiographic reconstruction of a patient with a bicuspid aortic valve demonstrating the 10 sections at which the aortic diameter was measured: $A$, aortoventricular junction; $B$, sinuses of Valsalva; $C$, sinotubular junction; $D$, tubular portion of the ascending aorta; $E$, proximal to the innominate trunk; $F$, distal to the innominate trunk; $G$, proximal to the left subclavian artery; $H$, distal to the left subclavian artery; $I$, proximal descending aorta; $J$, descending aorta at the diaphragm.

The patterns of cusp fusion in the 44 patients in whom echocardiograms were available for re-review were as follows: naturally perfect with no raphe (Sievers Type 0) in 4 (9\%), right/left cusp fusion (Sievers Type 1, R/L) in $31(71 \%)$, right/noncoronary cusp fusion (Sievers Type 1, $\mathrm{R} / \mathrm{N}$ ) in $8(18 \%)$, and left/noncoronary cusp fusion (Sievers Type $1, \mathrm{~L} / \mathrm{N})$ in $1(2 \%)$.
Measurements of aortic diameter at all levels in the entire cohort passed the normality test. Mean aortic diameter at the annulus was $28.1 \pm 0.7 \mathrm{~mm}$, and that at the diaphragmatic hiatus was $21.7 \pm 0.4 \mathrm{~mm}$. The largest aortic diameter was in the tubular portion of the ascending aorta, in which the mean diameter was $45.9 \pm 1.0 \mathrm{~mm}$. The aorta then tapered to normal diameter across the aortic arch; the mean diameter distal to the innominate artery was $30.1 \pm 0.8 \mathrm{~mm}$ (Figure 2, $A)$. When compared with the caliber of either the proximal or distal descending aorta, ascending aortic and arch diameters were significantly larger (Figure 2, A).

Comparison by sex showed similar dilation of the ascending aorta and transverse arch in male and female patients, although the relative degree of aortic dilation when indexed to the distal descending aorta was larger in women (Figure 2, $B)$. Analysis by age revealed greater dilation of the aortic sinuses and the sinotubular junction in younger patients (1829 years) relative to the distal descending aortic diameter (Figure $2, C$ ). The presence of any degree of aortic stenosis (mean gradient, $>10 \mathrm{~mm} \mathrm{Hg}$ ) or AI was not associated with aortic dilatation (Figure 2, $D$ and $E$ ). A bovine aortic arch was associated with less dilatation in the midarch (Figure 2, F).

Cluster analysis (Figure 3) demonstrated 4 distinct patterns of aortic dilation in these patients with BAVs. Cluster I patients $(n=8)$ had involvement of the aortic root. Cluster II patients $(\mathrm{n}=9)$ had involvement of the tubular portion of the ascending aorta. Cluster III patients $(n=18)$ had involvement of the tubular portion of the ascending aorta and transverse aortic arch. In these patients aortic diameters proximal and distal to the takeoff of the innominate artery were $46.3 \pm$ $6.2 \mathrm{~mm}$ and $35.9 \pm 4.8 \mathrm{~mm}$, respectively. In cluster IV patients $(n=29)$ the aortic dilatation was most diffuse, involving the aortic root, ascending aorta, and the proximal aortic arch. Aortic diameter was $41.6 \pm 6.5 \mathrm{~mm}$ at the sinuses of Valsalva, $46.7 \pm 8.6 \mathrm{~mm}$ in the tubular ascending aorta, $36.2 \pm 5.7 \mathrm{~mm}$ proximal to the innominate artery, and 29.1 $\pm 5.8 \mathrm{~mm}$ in the midarch. Cluster I contained the youngest patients and the highest proportion of female patients. Clusters I and IV, both of which had aortic root involvement, accounted for $73 \%$ of patients with a bovine aortic arch. The pattern of cusp fusion in each cluster is depicted in Figure 3, but cusp fusion pattern was not associated with any particular aortic morphology cluster pattern.

\section{Discussion}

When complete thoracic aortic imaging was available, we observed that aortic dilatation in patients with BAVs frequently involves the transverse aortic arch. More importantly, we found that patterns of aortic dilatation fell into 4 distinct categories. These separate morphologic patterns argue that an individualized and custom-tailored approach to aortic resection in patients with BAVs would be reasonable and should involve the aortic arch in the majority of cases. 

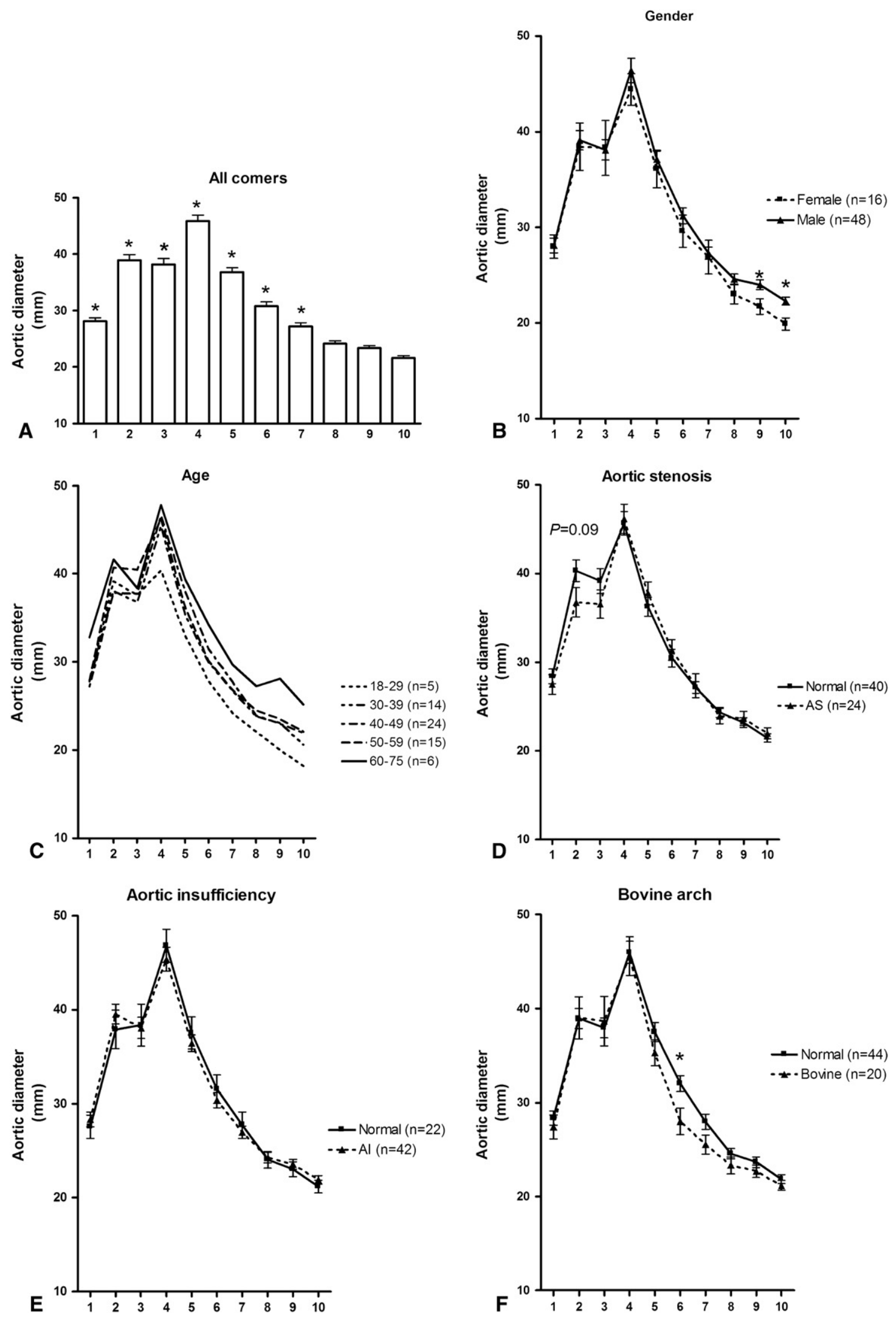
Natural history observational studies have suggested that an ascending aortic diameter of $6 \mathrm{~cm}$ (irrespective of whether the valve is bicuspid or tricuspid) is an indication for surgical graft replacement, with $6 \mathrm{~cm}$ being the hinge point beyond which there is a $30 \%$ increase in the probability of rupture. ${ }^{17}$ Patients who underwent isolated aortic valve replacement when the aortic diameter exceeded $5.1 \mathrm{~cm}$ experienced a risk of aortic dissection in excess of $20 \%$ compared with $0.6 \%$ in patients with no ascending aortic dilatation. ${ }^{18,19} \mathrm{E}$. Stanley Crawford first brought to our attention this grave surgical error of omission more than 20 years ago. Patients with BAVs undergoing aortic valve replacement commonly have substantial dilation of the ascending aorta, ${ }^{20}$ which continues to enlarge after aortic valve replacement. ${ }^{21}$ Furthermore, patients with BAVs with moderate aortic dilatation who undergo only aortic valve replacement sustain aortic dissection, rupture, and sudden death more frequently than similar patients with a tricuspid aortic valve. ${ }^{22-24}$ Based on these findings, the American College of Cardiology and American Heart Association practice guidelines have now adopted a more aggressive posture, favoring aortic replacement when the aorta is larger than $45 \mathrm{~mm}$ in patients with BAVs undergoing aortic valve replacement and $50 \mathrm{~mm}$ in patients with BAVs with isolated thoracic aortic aneurysms. ${ }^{25}$

The extent of the aorta that should be replaced, however, presently is unknown. In the present study $58 \%$ of patients had aortic root involvement (clusters I and IV), and 73\% of patients had involvement of the proximal arch (clusters III and IV). In the latter groups of patients, the aortic dilatation extended into the midarch in 35\%. This question of how much aorta to replace highlights the importance of relative aortic size, as introduced by Davies and colleagues, ${ }^{26}$ or of observed aortic size indexed to predicted aortic size, as first advocated by Legget and associates. ${ }^{27}$ Although the latter is likely to be more reliable in predicting adverse clinical events, it depends on accurate reference values that presently do not exist for the aortic arch. Furthermore, the impetus to replace all diseased aortic segments must be balanced against any incremental operative risk inherent in a more aggressive surgical approach.

Two main surgical options exist for the treatment of aortic root aneurysms: composite valve graft (CVG) or valve-sparing aortic root replacement. Both approaches can be carried with low operative mortality and excellent long-term outcomes. ${ }^{28,29}$ Compilation of our own results in the 5-year period covered by this report has shown that 1 of 126 patients undergoing elective mechanical CVG has died $(0.79 \%$ mortality rate). Similarly, none of the 106 patients undergoing elective reimplantation-type valve-sparing root replacement has died. Arguably, in young patients the more attractive option is valve-sparing aortic root replacement if the BAV cusps are not fibrotic or calcified, so that the patient avoids the thromboembolic and anticoagulant-related hemorrhagic complications of a CVG with a mechanical prosthesis. This approach, however, exposes the patient to a higher risk of reoperation when the valvular pathology progresses or the valve-sparing operation does not prove to be durable, but this increased risk is not clearly defined in the current literature. Another approach, which we do not recommend in this young patient population, is the separate valve graft, whereby the aortic valve and the supracoronary aorta are replaced separately. This procedure leaves diseased aortic sinuses behind and should only be undertaken when the patient is elderly and has significant comorbidity and is deemed to be unfit for a full aortic root replacement.

Total arch replacement is performed today with low morbidity and mortality in centers with experienced personnel. ${ }^{30}$ The decision for aortic arch replacement is made preoperatively on review of aortic imaging. The extent of resection then informs our choice of arterial cannulation. When aortic arch replacement is planned, patients either undergo cannulation of the axillary artery or the innominate artery. In all cases we use a combination of selective antegrade cerebral perfusion and hypothermia. Again, during the time interval of the present study, none of the 62 patients undergoing CVG and arch replacement and none of the 31 patients undergoing valve-sparing root replacement and arch replacement have died. However, it is realistic to expect some small increase in risk if the arch is replaced concomitantly at centers with less-experienced personnel. Despite this theoretic increased risk, we believe that total aortic arch replacement (frequently using the "peninsula technique," leaving a small tongue of greater curvature of the arch along the origins of the great vessels, which is more aggressive than the traditional beveled graft hemiarch replacement) should be carried out in the cluster III patients with BAVs whose aortas measure 46 $\mathrm{mm}$ just at the takeoff of the innominate artery. In patients in cluster IV, even an open distal anastomosis when replacing the ascending aorta will leave behind the proximal aortic arch, on average measuring $36 \mathrm{~mm}$. Given that the ascending

\begin{abstract}
Figure 2. Aortic dilation in patients with bicuspid aortic valves involves the aortic arch. A, Aortic diameters in all patients. ${ }^{*} P<.05$, Dunnett posttest compared with the aortic diameter at the diaphragmatic hiatus. B, Aortic diameters by sex. C, Aortic diameters by age. Younger patients had greater relative dilation of the aortic root relative to the distal descending aorta. D, Aortic diameters by presence of aortic stenosis. AS, Aortic stenosis. E, Aortic diameters by presence of aortic insufficiency. Al, Aortic insufficiency. F, Aortic diameters by presence of a bovine aortic arch. 1, Aortoventricular junction; 2, sinuses of Valsalva; 3, sinotubular junction; 4, tubular portion of the ascending aorta; 5, proximal to the innominate trunk; 6 , distal to the innominate trunk; 7 , proximal to the left subclavian artery; 8 distal to the left subclavian artery; 9 , proximal descending aorta; 10 , descending aorta at the diaphragm.
\end{abstract}



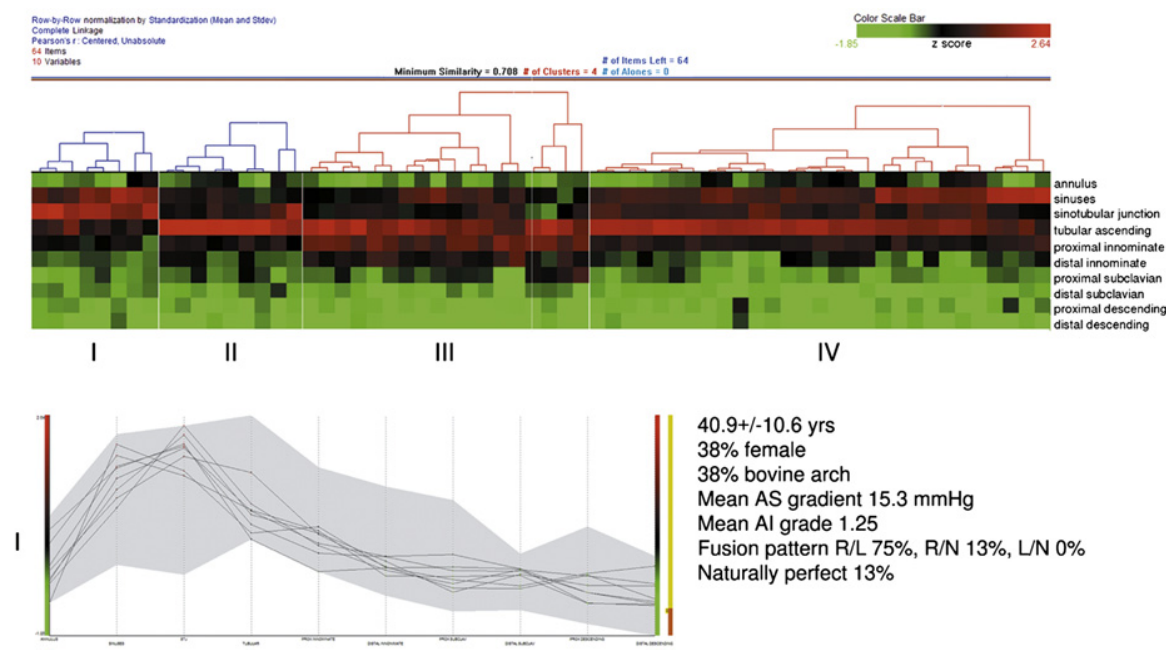

$40.9+/-10.6$ yrs

$38 \%$ female

$38 \%$ bovine arch

Mean AS gradient $15.3 \mathrm{mmH}$

Mean Al grade 1.25

Fusion pattern R/L 75\%, R/N 13\%, L/N 0\% Naturally perfect $13 \%$

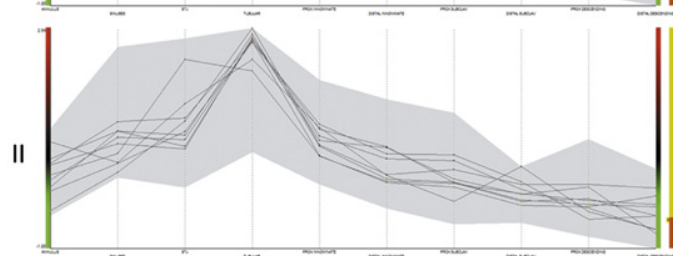

$48.4+/-11.2$ yrs

$13 \%$ female

$13 \%$ bovine arch

Mean AS gradient $6.9 \mathrm{mmHg}$

Mean Al grade 1.00

Fusion pattern R/L 100\%, R/N 0\%, L/N 0\%

Naturally perfect $0 \%$

$44.4+/-10.3$ yrs

$28 \%$ female

$22 \%$ bovine arch

Mean AS gradient $24.9 \mathrm{mmHg}$

Mean Al grade 1.35

Fusion pattern R/L 73\%, R/N 21\%, L/N 0\%

Naturally perfect $6 \%$

$46.1+/-13.2$ yrs

$24 \%$ female

$35 \%$ bovine arch

Mean AS gradient $11 \mathrm{mmHg}$

Mean Al grade 1.23

Fusion pattern R/L 79\%, R/N 10\%, L/N 3\%

Naturally perfect $7 \%$ aorta in patients with BAVs enlarges by approximately 0.9 to $1.9 \mathrm{~mm} / \mathrm{y},{ }^{31,32}$ it would take less than 15 years before the aortic arch would theoretically dilate to $50 \mathrm{~mm}$. These more aggressive strategies are warranted given the young age of these patients with BAVs, averaging 45 years in our present cohort. Using less-extensive aortic replacement places these patients with an underlying aortopathy at risk of either aortic catastrophe, which is frequently fatal, or requirement for later reoperation, which is a high-risk redo procedure. The decision to carry out a more extensive resection ought to be taken in light of the personal outcomes of the treating team. Less-experienced surgeons might wisely elect to avoid complete resection of the diseased aortic segments.

Several limitations temper the inferences that can be drawn from the present analysis. First, we do not presently have clinical data to support the notion that more aggressive aortic replacement will decrease postoperative morbidity and mortality over the long-term. Indeed, the retrospective natural history studies regarding how malignant or benign
Figure 3. Unsupervised hierarchic clustering of the data set revealed 4 distinct patterns of aortic dilation in patients with a bicuspid aortic valve. The top panel shows a "heat map" in which each column represents a patient and each row represents aortic diameters that have been color coded according to the calculated within-patient $z$ scores on a continuous scale shown on the top right corner of the panel. Cluster I patients had predominant involvement of the aortic root $(n=8)$. Cluster II patients had predominant involvement of the tubular portion of the ascending aorta $(n=9)$. Cluster III patients had involvement of the tubular portion of the ascending aorta and the transverse arch $(\mathbf{n}=18)$. Cluster IV patients had diffuse involvement of the thoracic aorta with dilation extending from the aortic root to the midtransverse $\operatorname{arch}(n=29)$. The 4 clusters are shown again in the bottom 4 panels, which depict the metric aortic diameters across the thoracic aorta for each individual patient. The clinical data for each cluster are summarized to the right of each cluster panel. AS, Aortic stenosis; Al, aortic insufficiency.

thoracic aortic aneurysms behave in patients with BAVs are conflicting. ${ }^{22,23,31,33}$

Second, we did not have access to all echocardiograms for personal re-review, which rendered our analysis of cusp fusion patterns and patterns of aortic dilation relatively underpowered.

Third, our snapshot analysis does not provide any longitudinal information concerning the fate of aortic aneurysms in patients with BAVs. In fact, the different clusters could theoretically represent the same pathology along a continuum.

Fourth, this patient sample is a selected cohort in which we had access to complete CTA or MRA thoracic aortic imaging. We are also unable to determine the total number of patients with BAVs who were treated at our institution during the study interval. If all patients with BAVs were subjected to more complete thoracic aortic imaging, the degree and extent of aortic dilation might differ.

Fifth, our patient population was not compared with patients with ascending aortic aneurysms who had a trileaflet 
aortic valve; based on current information, it is unclear how aneurysm extent and morphology differ between these patient subgroups. Nevertheless, we must take to heart Dr John S. Child's plea that we must now abandon the terms "poststenotic dilation" and "postregurgitant dilation" in describing the dilated aorta that accompanies a BAV because these patients have an underlying connective tissue disorder and the aneurysmal dilation is not a consequence of the coexistent valvular hemodynamic abnormality. ${ }^{15}$

We conclude that aortic dilatation in patients with BAVs follows 4 distinctive patterns that militate for an individualized, custom-tailored degree of ascending aortic and arch replacement. Patients in clusters III and IV requiring operations should have the transverse arch replaced and not just the ascending aorta (along with concomitant root replacement in cluster IV). In cluster I patients complete aortic root replacement (reimplantation type valve-sparing or CVG) is necessary, whereas in cluster II patients a supracommissural ascending aortic graft is adequate. This individualized approach is our practice and should minimize the incidence of late aortic complications and need for reoperation.

We thank Ms Sharmi Shafi for her contribution in collating a list of bibliographic references.

\section{References}

1. Ratib O, Perloff JK, Child JS. Images in cardiovascular medicine. Bicuspid aortic valve aneurysm. Circulation. 2004;109:671.

2. de Sa M, Moshkovitz Y, Butany J, David TE. Histologic abnormalities of the ascending aorta and pulmonary trunk in patients with bicuspid aortic valve disease: clinical relevance to the Ross procedure. $J$ Thorac Cardiovasc Surg. 1999;118:588-94.

3. Alegret JM, Duran I, Palazon O, Vernis JM, Ameijide A, Rabassa A, et al. Prevalence of and predictors of bicuspid aortic valves in patients with dilated aortic roots. Am J Cardiol. 2003;91:619-22.

4. Nkomo VT, Enriquez-Sarano M, Ammash NM, Melton LJ III, Bailey KR, Desjardins V, et al. Bicuspid aortic valve associated with aortic dilatation: a community-based study. Arterioscler Thromb Vasc Biol. 2003;23:351-6.

5. Novaro GM, Tiong IY, Pearce GL, Grimm RA, Smedira N, Griffin BP. Features and predictors of ascending aortic dilatation in association with a congenital bicuspid aortic valve. Am J Cardiol. 2003;92:99-101.

6. Pachulski RT, Chan KL. Progression of aortic valve dysfunction in 51 adult patients with congenital bicuspid aortic valve: assessment and follow up by Doppler echocardiography. Br Heart J. 1993;69:237-40.

7. Cecconi M, Nistri S, Quarti A, Manfrin M, Colonna PL, Molini E, et al. Aortic dilatation in patients with bicuspid aortic valve. J Cardiovasc Med (Hagerstown). 2006;7:11-20.

8. Bauer M, Gliech V, Siniawski H, Hetzer R. Configuration of the ascending aorta in patients with bicuspid and tricuspid aortic valve disease undergoing aortic valve replacement with or without reduction aortoplasty. J Heart Valve Dis. 2006; 15:594-600.

9. Fedak PW, Verma S, David TE, Leask RL, Weisel RD, Butany J. Clinical and pathophysiological implications of a bicuspid aortic valve. Circulation. 2002;106:900-4.

10. Niwa K, Perloff JK, Bhuta SM, Laks H, Drinkwater DC, Child JS, et al. Structural abnormalities of great arterial walls in congenital heart disease: light and electron microscopic analyses. Circulation. 2001;103:393-400.

11. Grotenhuis HB, Ottenkamp J, Westenberg JJ, Bax JJ, Kroft LJ, de Roos A. Reduced aortic elasticity and dilatation are associated with aortic regurgitation and left ventricular hypertrophy in nonstenotic bicuspid aortic valve patients. J Am Coll Cardiol. 2007;49:1660-5.

12. Larson EW, Edwards WD. Risk factors for aortic dissection: a necropsy study of 161 cases. Am J Cardiol. 1984;53:849-55.
13. Ward C. Clinical significance of the bicuspid aortic valve. Heart. 2000; 83:81-5.

14. Edwards WD, Leaf DS, Edwards JE. Dissecting aortic aneurysm associated with congenital bicuspid aortic valve. Circulation. 1978;57: $1022-5$.

15. Braverman AC, Guven H, Beardslee MA, Makan M, Kates AM, Moon MR. The bicuspid aortic valve. Curr Probl Cardiol. 2005;30:470-522.

16. D'Haeseleer P. How does gene expression clustering work? Nat Biotechnol. 2005;23:1499-501.

17. Elefteriades JA. Natural history of thoracic aortic aneurysms: indications for surgery, and surgical versus nonsurgical risks. Ann Thorac Surg. 2002;74(suppl):S1877-80.

18. Pieters FA, Widdershoven JW, Gerardy AC, Geskes G, Cheriex EC, Wellens HJ. Risk of aortic dissection after aortic valve replacement. Am J Cardiol. 1993;72:1043-7.

19. Prenger K, Pieters F, Cheriex E. Aortic dissection after aortic valve replacement: incidence and consequences for strategy. J Card Surg. 1994;9:495-8.

20. Morgan-Hughes GJ, Roobottom CA, Owens PE, Marshall AJ. Dilatation of the aorta in pure, severe, bicuspid aortic valve stenosis. Am Heart J. 2004;147:736-40.

21. Yasuda H, Nakatani S, Stugaard M, Tsujita-Kuroda Y, Bando K, Kobayashi J, et al. Failure to prevent progressive dilation of ascending aorta by aortic valve replacement in patients with bicuspid aortic valve: comparison with tricuspid aortic valve. Circulation. 2003;108(suppl 1):II291-4.

22. Borger MA, Preston M, Ivanov J, Fedak PW, Davierwala P, Armstrong S, et al. Should the ascending aorta be replaced more frequently in patients with bicuspid aortic valve disease? J Thorac Cardiovasc Surg. 2004;128:677-83.

23. Russo CF, Mazzetti S, Garatti A, Ribera E, Milazzo A, Bruschi G, et al. Aortic complications after bicuspid aortic valve replacement: long-term results. Ann Thorac Surg. 2002;74(suppl):S1773-6.

24. Matsuyama K, Usui A, Akita T, Yoshikawa M, Murayama M, Yano T, et al. Natural history of a dilated ascending aorta after aortic valve replacement. Circ J. 2005;69:392-6.

25. Bonow RO, Carabello BA, Kanu C, de Leon AC Jr, Faxon DP, Freed MD, et al. ACC/AHA 2006 guidelines for the management of patients with valvular heart disease: a report of the American College of Cardiology/American Heart Association Task Force on Practice Guidelines (writing committee to revise the 1998 Guidelines for the Management of Patients With Valvular Heart Disease): developed in collaboration with the Society of Cardiovascular Anesthesiologists: endorsed by the Society for Cardiovascular Angiography and Interventions and the Society of Thoracic Surgeons. Circulation. 2006;114:e84-231.

26. Davies RR, Gallo A, Coady MA, Tellides G, Botta DM, Burke B, et al. Novel measurement of relative aortic size predicts rupture of thoracic aortic aneurysms. Ann Thorac Surg. 2006;81:169-77.

27. Legget ME, Unger TA, O'Sullivan CK, Zwink TR, Bennett RL, Byers PH, et al. Aortic root complications in Marfan's syndrome: identification of a lower risk group. Heart. 1996;75:389-95.

28. David TE, Feindel CM, Webb GD, Colman JM, Armstrong S, Maganti M. Long-term results of aortic valve-sparing operations for aortic root aneurysm. J Thorac Cardiovasc Surg. 2006;132:347-54.

29. Gott VL, Greene PS, Alejo DE, Cameron DE, Naftel DC, Miller DC, et al. Replacement of the aortic root in patients with Marfan's syndrome. N Engl J Med. 1999;340:1307-13.

30. Elefteriades JA, Dobrilovic N, Gega A. A new surgical paradigm: hybrid open and endovascular repair of the ascending aorta and aortic arch for acute type A dissection [letter]. J Thorac Cardiovasc Surg. 2007;132:735.

31. Davies RR, Kaple RK, Mandapati D, Gallo A, Botta DM Jr, Elefteriades JA, et al. Natural history of ascending aortic aneurysms in the setting of an unreplaced bicuspid aortic valve. Ann Thorac Surg. 2007:83:1338-44.

32. Ferencik M, Pape LA. Changes in size of ascending aorta and aortic valve function with time in patients with congenitally bicuspid aortic valves. Am J Cardiol. 2003;92:43-6.

33. Goland S, Czer LS, De Robertis MA, Mirocha J, Kass RM, Fontana GP, et al. Risk factors associated with reoperation and mortality in 252 patients after aortic valve replacement for congenitally bicuspid aortic valve disease. Ann Thorac Surg. 2007;83:931-7. 

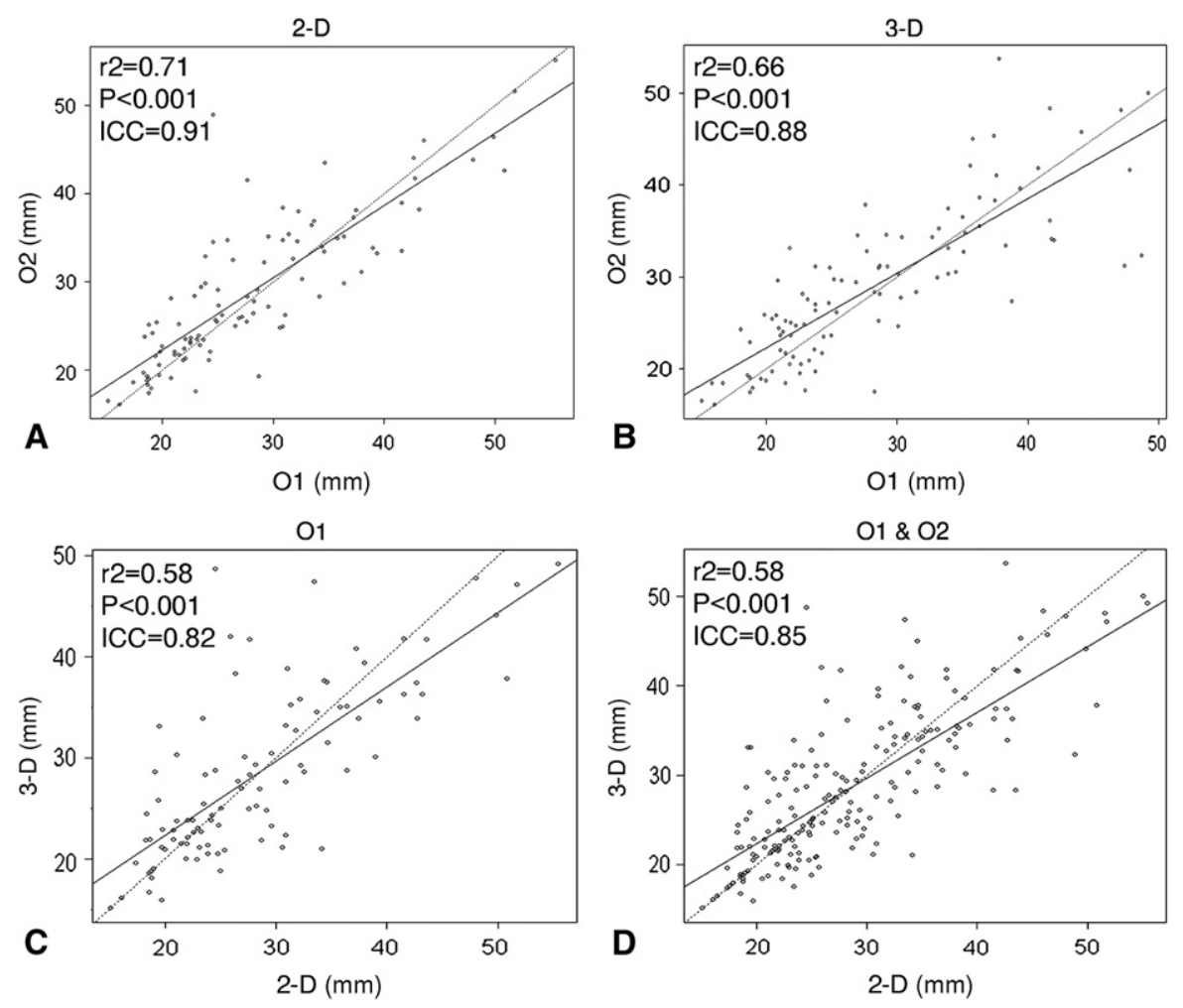

Figure E1. Interobserver and intertechnique variability. A, Interobserver variability by using the 2-dimensional (2-D) axial images. $B$, Interobserver variability by using the 3-dimensional (3-D) reconstructed images. C, Intertechnique variability between the 3-dimensional and 2-dimensional measurements made by observer 1. D, Intertechnique variability between the 3-dimensional and 2-dimensional measurements made by observers 1 and 2 . In all subpanels the line of unity is depicted by the dashed line. The continuous line depicts the linear regression fit through the actual data points. 01, Observer 1; 02, observer 2; ICC, interclass correlation. 
TABLE E1. Bland-Altman confidence intervals and interclass correlations for interobserver and intertechnique variations

\begin{tabular}{|c|c|c|c|c|}
\hline & Mean difference & Lower limit & Upper limit & ICC \\
\hline \multicolumn{5}{|l|}{$2-D$} \\
\hline Aortic sinus & 1.92 & -8.8 & 12.6 & 0.6654 \\
\hline Tubular ascending aorta & 1.15 & -4.6 & 6.9 & 0.9696 \\
\hline Distal to subclavian artery & 0.69 & -3.5 & 4.8 & 0.8639 \\
\hline Distal descending aorta & 0.25 & -4.3 & 4.8 & 0.6454 \\
\hline \multicolumn{5}{|l|}{$3-D$} \\
\hline Aortic sinus & 3.15 & -8.8 & 15.6 & 0.4791 \\
\hline Tubular ascending aorta & -3.91 & -14 & 6.2 & 0.5996 \\
\hline Distal to subclavian artery & -0.44 & -5.7 & 4.8 & 0.3346 \\
\hline Distal descending aorta & 0.01 & -5.2 & 5.2 & 0.6249 \\
\hline \multicolumn{5}{|l|}{ 2-D vs 3-D } \\
\hline Aortic sinus & -1.71 & -13 & 10 & 0.5223 \\
\hline Tubular ascending aorta & 1.52 & -9.7 & 13 & 0.6187 \\
\hline Distal to subclavian artery & 1.02 & -6.33 & 8.37 & 0.2594 \\
\hline Distal descending aorta & -0.75 & -3.64 & 2.14 & 0.9282 \\
\hline
\end{tabular}

ICC, Interclass correlation; 2-D, 2-dimensional; 3-D, 3-dimensional. 